\title{
Uso de técnicas de gestão de recursos na redução de paradas industriais não
}

\section{planejadas}

\author{
Use of resource management techniques to reduce unplanned industrial shutdowns \\ Uso de técnicas de gestión de recursos para reducir las paradas industriales no planificadas
}

Recebido: 18/05/2021 | Revisado: 24/05/2021 | Aceito: 29/05/2021 | Publicado: 13/06/2021

Ellen Caroline Martins Anchieta

ORCID: https://orcid.org/0000-0002-9493-0473

Centro Universitário Santo Agostinho, Brasil

E-mail: ellenanchieta@gmail.com

Luís Henrique Dos Santos Silva Sousa

ORCID: https://orcid.org/0000-0002-2269-1813

Centro Universitário Santo Agostinho, Brasil E-mail: luishenrique@unifsa.com.br

\begin{abstract}
Resumo
A busca incessante pela vantagem competitiva no ramo industrial colabora para que seja percebida a importância do controle dos recursos primários da produção. Esta pesquisa se fundamenta pelo alto índice de ociosidade gerado pela carência dos recursos primordiais para fabricação do produto, interligado à falta de manejo destes. O objetivo deste estudo é identificar e analisar os índices de parada produtiva por falta de matéria prima, propor melhorias que assegurem uma fluidez clara do processo e ganho de produtividade pelos operadores, além de servir de auxílio aos gestores nas tomadas de decisões. Caracteriza-se como estudo de caso através da observação direta e pesquisa bibliográfica, além de ter uma abordagem mista (quali-quantitativa) evidenciada pela descrição de uma pesquisa explicativa. Foram explorados dados colhidos na empresa para construção da solidez do artigo, por meio dos números de paradas produtivas, produtos acabados afetados pela falta de material e principais itens e suas respectivas frequência de absenteísmo no estoque. Desta forma, foi possível construir a curva ABC dos produtos acabados e das matérias primas permitindo visualizar os materiais que demandam maior atenção e cuidado para manter sempre ativo no almoxarifado, pois são aqueles que mais giram no armazém. Por fim, através da análise das informações, concluise que se faz necessário uma reestruturação na lista de materiais dos produtos acabados para que assim, seja possível rodar o MRP, além da adoção de uma rotina de inventários rotativos baseados na Curva ABC de insumos para gerar índices de acuracidade e garantir o controle dos processos.
\end{abstract}

Palavras-chave: Curva ABC; Gestão de estoque; Panejamento e controle da produção; MRP.

\begin{abstract}
The relentless pursuit of competitive advantage in the industrial sector contributes to the realization of the importance of controlling primary production resources. This research is based on the high index of idleness generated by the lack of essential resources for the manufacture of the product, linked to the lack of management of these. The objective of this study is to identify and analyze the production stoppage rates due to lack of raw material, to propose improvements that ensure clear process fluidity and productivity gains for operators, in addition to helping managers in decision making. It is characterized as a case study through direct observation and bibliographic research, in addition to having a mixed approach (quali-quantitative) evidenced by the description of an explanatory research. Data collected in the company were explored to build the solidity of the article, through the numbers of production stops, finished products affected by the lack of material and main items and their respective frequency of absenteeism in the stock. In this way, it was possible to build the ABC curve of finished products and raw materials, allowing the visualization of materials that demand greater attention and care to always keep active in the warehouse, as they are the ones that most rotate in the warehouse. Finally, through the analysis of the information, it is concluded that it is necessary to restructure the material list of the finished products so that it is possible to run the MRP, in addition to the adoption of a routine of rotating inventories based on the ABC Curve of inputs to generate accuracy indexes and ensure control of processes.
\end{abstract}

Keywords: ABC curve; Stock management; Planning and production Control; MRP.

\section{Resumen}

La búsqueda incesante de ventajas competitivas en el sector industrial contribuye a la comprensión de la importancia de controlar los recursos de producción primaria. Esta investigación se basa en el alto índice de ociosidad que genera la falta de recursos imprescindibles para la fabricación del producto, ligado a la falta de gestión de estos. El objetivo 
de este estudio es identificar y analizar las tasas de paralización de la producción por falta de materia prima, para proponer mejoras que aseguren una clara fluidez del proceso y ganancias de productividad para los operadores, además de ayudar a los gerentes en la toma de decisiones. Se caracteriza por ser un estudio de caso mediante observación directa e investigación bibliográfica, además de tener un enfoque mixto (cuali-cuantitativo) evidenciado por la descripción de una investigación explicativa. Se exploraron los datos recolectados en la empresa para construir la solidez del artículo, a través de los números de paradas de producción, productos terminados afectados por la falta de material y rubros principales y su respectiva frecuencia de absentismo en el stock. De esta forma, fue posible construir la curva $\mathrm{ABC}$ de productos terminados y materias primas, permitiendo la visualización de materiales que demandan mayor atención y cuidado para mantenerse siempre activos en el almacén, ya que son los que más giran en el almacén. Finalmente, a través del análisis de la información, se concluye que es necesario reestructurar la lista de materiales de los productos terminados para que sea posible ejecutar el MRP, además de la adopción de una rutina de inventarios rotativos basada en el ABC. Curva de insumos para generar índices de precisión y asegurar el control de procesos.

Palabras clave: Curva ABC; La gestión del inventario; Planificación y control de producción; MRP.

\section{Introdução}

Grande parte das empresas do setor industrial ainda comete falhas por adotar meios extremos de controle de materiais em seu processo produtivo, havendo excesso ou ausência de estoque de insumos, afetando diretamente todo o planejamento da produção. Em geral, por falta de recursos financeiros suficientes e/ou pouco espaço para armazenamento, as indústrias de pequeno e médio portes sofrem por ausência de matéria prima nas suas operações, somado ao fato de que muitas organizações negligenciam o controle dos materiais atrelados à produção.

Desta forma, um dos pontos que mais afetam os setores onde ocorrem as atividades produtivas é a falta de matéria prima no decorrer do seguimento das atividades, consequentemente causando ociosidade nos colaboradores por causa da parada não programada. Um software com MRP (Material Requirement Planning) incluso e a aplicação de ferramentas de administração dos materiais disponíveis no almoxarifado são de extrema necessidade e tornam-se um diferencial competitivo, porquanto a maioria das organizações encontram-se sensíveis e ainda não adotaram completamente estas medidas de controle dentro do seu sistema.

Este estudo é direcionado para engenheiros de produção e gestores atuantes nos setores de produção, PPCP (Programação, planejamento e controle da produção) e estoque para servir de apoio nas tomadas de decisões referentes às paradas não planejadas no processo industrial.

Por conseguinte, este artigo se divide em 5 partes, sendo elas: introdução, metodologia, referencial teórico, resultados, discussões e conclusão tendo como objetivo identificar os efeitos da ausência de matéria prima na produção e sua influência no índice de paradas produtivas em uma indústria, além de mostrar como a aplicação de técnicas de gestão podem aumentar os indicadores contribuindo com a continuidade do fluxo produtivo.

\section{Referencial Teórico}

Neste tópico serão explicados, com profundidade, os principais temas relacionados a este trabalho, sendo eles: curva $\mathrm{ABC}$, gestão de estoque, planejamento e controle da produção e MRP, tendo como embasamento teórico principal a obra Administração de materiais: uma abordagem logística de (Dias, 2010) e artigos encontrados nos anais de eventos e em revistas da área, objetivando antecipar o entendimento do leitor a respeito dos assuntos tratados na pesquisa.

\subsection{Planejamento e Controle da Produção}

Em suas pesquisas, Fernandes e Godinho (2010) interpretaram PCP (Planejamento e controle de Produção) como um conjunto de estratégias com propósito de entender e calcular quanto, como, onde e quando produzir e, a partir destas variáveis, tomar decisões buscando programar, planejar e controlar as atividades produtivas. 
Complementando os autores supracitados, Rodrigues e Inácio (2010) colocam o PCP como um ponto de gestão que equilibra os setores de maiores expressões em uma empresa: compras (responsáveis pelas entradas de materiais), produção (setor de transformação) e logística (área encarregada de planejar as saídas de produtos) através do alinhamento da programação da produção e controle das atividades produtivas, realizando o repasse destas informações para os devidos setores.

Esta etapa dispõe de atividades que são executadas pelos três níveis hierárquicos de uma organização, sendo eles:

- Nível Estratégico: Onde são pautadas e elaboradas as atividades a serem exercidas no plano de produção, embasado a partir do planejamento estratégico da empresa.

- Nível Tático: É elaborado o Plano Mestre de Produção (PMP) que consiste em um dimensionamento das ordens de produção, compras de recursos, entrega dos produtos no prazo estabelecido. Todas as ações correspondentes ao processo produtivo devem estar inclusas no PMP.

- Nível Operacional: Acompanhamento e controle das operações fabris, gerenciamento do estoque e liberação de ordens de produção (Santos, Victor, \& Silva, 2010).

\subsection{Gestão de estoque}

Baseado em Betts, Chambers, Jonhston e Slack (2013) o sucesso das empresas deve-se principalmente à sua forma de aproveitamento dos recursos disponíveis, não importando a sua natureza, até conseguir uma estabilidade. Como dito por (Silva \& Henzel, 2012), estoques são acervos de insumos que serão utilizados para atender aos pedidos da produção ou aos critérios estabelecidos pelos clientes. Em contrapartida, Corrêa, Gianesi e Caon (2010) propõem que os estoques significam excesso de material nos pontos de fabricação, porém concordam que são essenciais para garantir a eficácia no fluxo de produção, devido a forma como funciona a logística e controle de insumos nas empresas.

De acordo com Razzolini (2012), uma empresa que possui uma gestão de estoque eficaz tem materiais disponíveis para utilizar no momento que quiser. Neste sentido, uma gestão eficiente de estoque é tida como diferencial competitivo, já que é uma dificuldade de muitos empreendimentos. Por isso, muitas empresas estão mais atentas a este fator para conseguir um destaque frente ao mercado. Além de que, é possível aumentar seu capital de retorno financeiro através de um bom planejamento e dimensionamento do estoque, pois são elevadas a eficiência das operações produtivas e, por fim, este bom gerenciamento contribui na redução do valor monetário investido, porém ainda sendo o suficiente para manter os volumes e atender a demanda (Borges, Campos, \& Borges, 2010).

\subsection{Administração dos materiais}

Como mencionado por Suzano (2013), a administração de materiais se conceitua como um conglomerado de ações, contemplando compras, armazenagem e recebimento de materiais, transporte e entrega dos mesmos ao cliente final, afim de atender às demandas solicitadas. Em consonância com o que foi dito anteriormente, Severo (2006) acrescentou que administrar materiais significa programar, preparar e examinar os recursos necessários à organização reduzindo tempo e otimizando o estoque, almejando o cumprimento dos objetivos propostos.

A administração de materiais está diretamente relativa à gestão de estoque e a fusão destes resulta em um declínio de custos operacionais (Pozo, 2002). Acrescentado a isto, os locais de armazenamento começam a ficar mais vagos, pois os materiais estão organizados estrategicamente e existe sobra de espaço para os demais, e virtude disto, os custos de estoques 
diminuem dentro do almoxarifado e ocorre a queda do número de movimentações internas com transporte de materiais buscando s devida distribuição (Gonçalves, 2013).

Logo, quando os recursos são efetivamente administrados é possível identificar benefícios e avanços no processo, tais como: diminuição de compras dispensáveis, os colaboradores dominam as descrições, dimensões e conhecem o uso do material, além de moderar consideravelmente as avarias, pois o material tem um local específico e identificado no estoque, reduzindo o número de movimentações dos operadores com este componente, evitando os danos, em adição ao planejamento desejável e bem monitorado das compras (Costa, 2002).

\subsubsection{Curva ABC}

Por ser uma classificação simples de ser executada, a curva $\mathrm{ABC}$ é uma das metodologias mais utilizadas na gestão de estoque, pois são práticas para delinear preferências no processo, sendo assim, auxilia na tomada de decisões a respeito de qual material deverá ser priorizado na produção (Dias, 2010).

Desta maneira, Leal, Cotrim e Nardotto (2016) citaram que por basear-se também em referências de custo, a classificação $\mathrm{ABC}$ permite que estes números sejam mais próximos da realidade completando os relatórios de execução das atividades industriais.

Uma das principais vantagens desta ferramenta para (Vago, Sousa, Melo, Lara, Fagundes, \& Sampaio, 2013) é apresentar os itens que impactam em menor escala no faturamento da empresa e são identificados como C, sendo que não deveriam estar no estoque, pois acarreta em perda financeira e de armazenamento com esse material parado. Complementando estas ideias, Letti e Gomes (2014) revelam que esta curva é a forma mais clara e acessível de se obter melhorias no estoque com a ajuda dos dados colocados no software da empresa e conforme os resultados são monitorados. No Quadro 1 é possível verificar como funciona cada elemento desta matriz.

Quadro 1 - Representação dos dados da Curva ABC.

\begin{tabular}{|c|c|c|}
\hline Classe & Percentual (\%) & Grau de impacto financeiro \\
\hline Classe A & 80 & Alto \\
\hline Classe B & 15 & Médio \\
\hline Classe C & 5 & Baixo \\
\hline & & \\
\hline
\end{tabular}

Fonte: Autores (2021).

Os elementos dispostos na classe A são uma quantia menor, mas que representam um maior valor monetário. Os itens desta classe são aqueles que tem mais giro dentro do estoque, as demais classificações B e C contem mais quantidade de itens, porém com menos impacto econômico e menos giro.

\subsubsection{Planejamento das Necessidades de Materiais - MRP}

O MRP tem como função central dar suporte às definições das necessidades de materiais, contemplando as quantidades, descrições e tempo correto de adquirir tais recursos. Portanto, é importante frisar a importância dos cálculos dos insumos indispensáveis à produção para que surja segurança ao comprar no tempo adequado, evitando atrasos na produção (Ribeiro, Carmo, Lobato, Pinho, \& Lopes, 2015). 
Esta ferramenta concede as empresas estudarem a indispensabilidade da matéria prima dos mais variados tipos, utilizando informações dispostas nos dados de entrada (data, fornecedor, número do pedido), os pedidos em carteira, ou seja, pedidos pendentes e a predição das vendas (Lopes, Silva, \& Rocha, 2014).

No ramo industrial, em destaque em empresas de pequeno e médio porte, a utilização de softwares de gestão integrada (ERP), contendo o MRP, teve uma elevação acentuada devido ao enfoque posto sobre os insumos e a relevância de programar sua aquisição em decorrência do consumo dos componentes pelos produtos acabados e, por esta razão, são utilizadas as listas de materiais, que auxiliam na montagem de um planejamento eficaz e facilitam o cálculo das necessidades de acordo com a demanda de cada produto final.

Em geral, estes softwares ERP executam automaticamente o MRP sempre que alertados sobre alguma urgência na requisição de material e, em tal caso, as entregas são organizadas gerando pedidos de compras instantâneo (Bento, Tambosi, \& Prus, 2013). Desta forma, o comercial não sofre sobrecarga por conta das requisições de material advindos da produção e o setor fabril não sofre perdas de produtividade.

\subsubsection{Inventários}

Grande parte dos erros encontrados no estoque são solucionados de maneira simples e prática através do controle dos processos de entrada e saída e treinamento dos colaboradores sem que seja preciso um investimento alto (Brown, Inman, \& Calloway, 2001).

O inventário representa uma correção do estoque físico registrado no sistema de uma empresa, sendo geralmente aplicado quando há uma grande divergência entre o físico e o "virtual". Em que devem ser contados os itens para garantir o controle da empresa (Oliveira, Chieregato, Gomes, \& Peres, 2009). Além de ser utilizado como uma ferramenta de análise e conferência da alimentação dos dados de entrada e saída e verificação da ocorrência de extravios de mercadorias. Como existe uma variedade de estoques, sendo eles do mais simples ao mais rebuscado e complexo, o inventário pode ser classificado da seguinte forma:

- Inventário Geral: Abrange a contagem de todos os itens disponíveis na empresa, desde o almoxarifado até o setor de distribuição;

- Inventário Parcial: Trata-se da contagem de uma parte específica de itens da organização, sendo assim, este modelo é dividido em setor;

- Inventário Anual: Contagem de toda a mercadoria no final do presente ano;

- Inventário Rotativo: Aborda a contagem feita de maneira repetitiva, podendo ser realizada mensalmente, semanalmente ou diariamente, variando de negócio para negócio. Esta tática é utilizada quando existem produtos com alto giro e é necessário que seja feita essa checagem em um curto intervalo de tempo;

- Inventário Cíclico: Consiste na verificação dos dados utilizados no lançamento contábil com a quantia de produtos contidos na empresa (Oliveira, Chieregato, Gomes, \& Peres, 2009).

\subsubsection{Acuracidade de estoque}

Um dos indicadores mais comuns de serem constantemente controlados são os indicadores de acuracidade. Sendo assim, Waller, Nachtmann e Hunter (2006) determina que os dados coletados do inventário físico devem estar bem descritos e detalhados para que não haja divergência por pequenas falhas que poderiam ser evitados.

Em razão disso, Bertaglia (2006) afirmou que o grau de acurácia é medido a partir da seguinte razão: 


\section{Acuracidade $=\frac{\text { Quantidade presente no estoque físico } x 100}{\text { Quantidade presente wo sistema }}$}

O índice de acuracidade é medido em porcentagem e quanto maior for o resultado, mais confiável é seu estoque. Esse indicador com valor alto é colocado como meta em diversas empresas, pois um estoque organizado e confiável é, de certa forma, uma garantia da qualidade e confiabilidade dos processos de uma empresa.

Fernandes e Pires (2005) estudaram os maiores impactos causados na produção a partir do baixo nível de acuracidade do estoque, sendo estes:

- Visão distorcida da empresa diante dos clientes;

- Atraso nas entregas do(s) produto(s) solicitado(s);

- Bloqueio no planejamento e programação da produção;

- Baixa confiabilidade dos setores na hora de produzir ou requisitar algum material;

- Reclamações internas, principalmente entre almoxarifado, setor de compras e produção.

Frisando o que foi mencionado pelo autor supracitado, listou as principais razões para inacuracidade do estoque é dada por:

1. Erros operacionais: Por diversas vezes, pode haver interferência da falha humana no momento da contagem. Anotações erradas ou registro realizado indevidamente são exemplos que ocasionam nas discrepâncias entre o saldo físico e o do sistema;

2. Danos ao produto: A presença de avarias nos materiais também é um fator que auxilia na baixa acurácia;

3. Extravio: Os pequenos furtos podem partir dos funcionários, fornecedores ou por terceiros que tiveram acesso ao local (Rekik, 2006).

\section{Metodologia}

A classificação da pesquisa de acordo os tipos de abordagem, objetivos e métodos se encontra sintetizada no Quadro a seguir:

Quadro 2 - Relação de classificação da pesquisa.

\begin{tabular}{|c|c|}
\hline Classificação da pesquisa & Tipo de abordagem \\
\hline Quanto aos procedimentos técnicos & Estudo de caso e pesquisa bibliográfica \\
\hline Quanto aos objetivos & Pesquisa Explicativa \\
\hline Quanto ao método de abordagem & Pesquisa quali-quantitativa \\
\hline Quanto ao método de procedimento & Método estatístico descritivo \\
\hline Quanto à síntese de dados & Método dedutivo \\
\hline
\end{tabular}

Fonte: Autores (2021).

Quanto aos procedimentos técnicos, a pesquisa é classificada como estudo de caso, através da observação direta dos fenômenos, com envolvimento indireto de pessoas, que causam a ausência de matéria prima no estoque e suas respectivas paradas não programadas e a partir disso, serão relatadas detalhadamente as evidências, avaliadas as causas e propor melhorias para solucionar o problema em questão. Nesta mesma classificação será utilizada a pesquisa bibliográfica, tendo o 
embasamento teórico a consulta em livros, artigos, periódicos e revistas que disponham de diferentes visões a respeito do PCP, estoque e administração de materiais no ambiente industrial.

Figura 1 - Etapas da pesquisa.

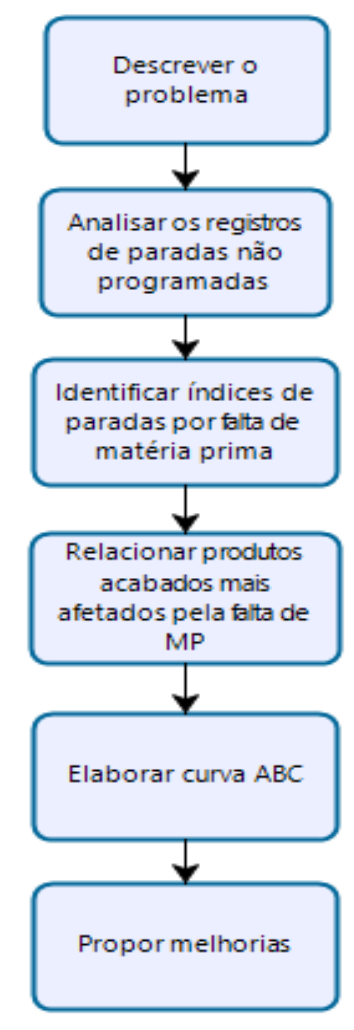

Fonte: Autores (2021).

Conforme classificação dos objetivos, o estudo caracteriza-se como pesquisa explicativa, derivados da identificação dos fatores que consolidam as ocorrências, neste caso, as paradas não programadas, sendo estes bem detalhados ao decorrer da análise, além de explicar o porquê das causas e efeitos (Gil, 1994). Em relação ao método de abordagem, trata-se de uma pesquisa quanti-qualitativa, devido a exploração de dados numéricos coletados, extraídos do sistema ERP Nomus utilizado pela empresa, complementados à explicação e análise destes resultados. Quanto aos métodos de procedimentos, será utilizado o estatístico descritivo, necessário no momento de construção de gráficos e tabelas, a partir das informações obtidos. Por fim, na síntese dos dados obtidos adjuntos à resolução do problema de pesquisa, será explorado o método dedutivo, no intuito de inferir conclusões sobre os fatos descritos.

\section{Resultados e Discussão}

Nesta seção serão apresentados os dados para contextualização e análise do problema de parada de produção, bem como suas representações gráficas e estratificação dos resultados obtidos em consultas do sistema da empresa. Além de evidenciar os pontos de maior criticidade e propor melhorias para resolução deste gargalo. 


\subsection{Contextualização do Problema}

Garantir a eficiência do fluxo de um processo produtivo é o princípio básico de toda a cadeia hierárquica de uma empresa. Os setores desse processo são divididos pela forma como ocorre a transformação do material em cada local, como representado na Figura 2.

Figura 2 - Visão geral do processo produtivo da fabricação dos produtos de aço.

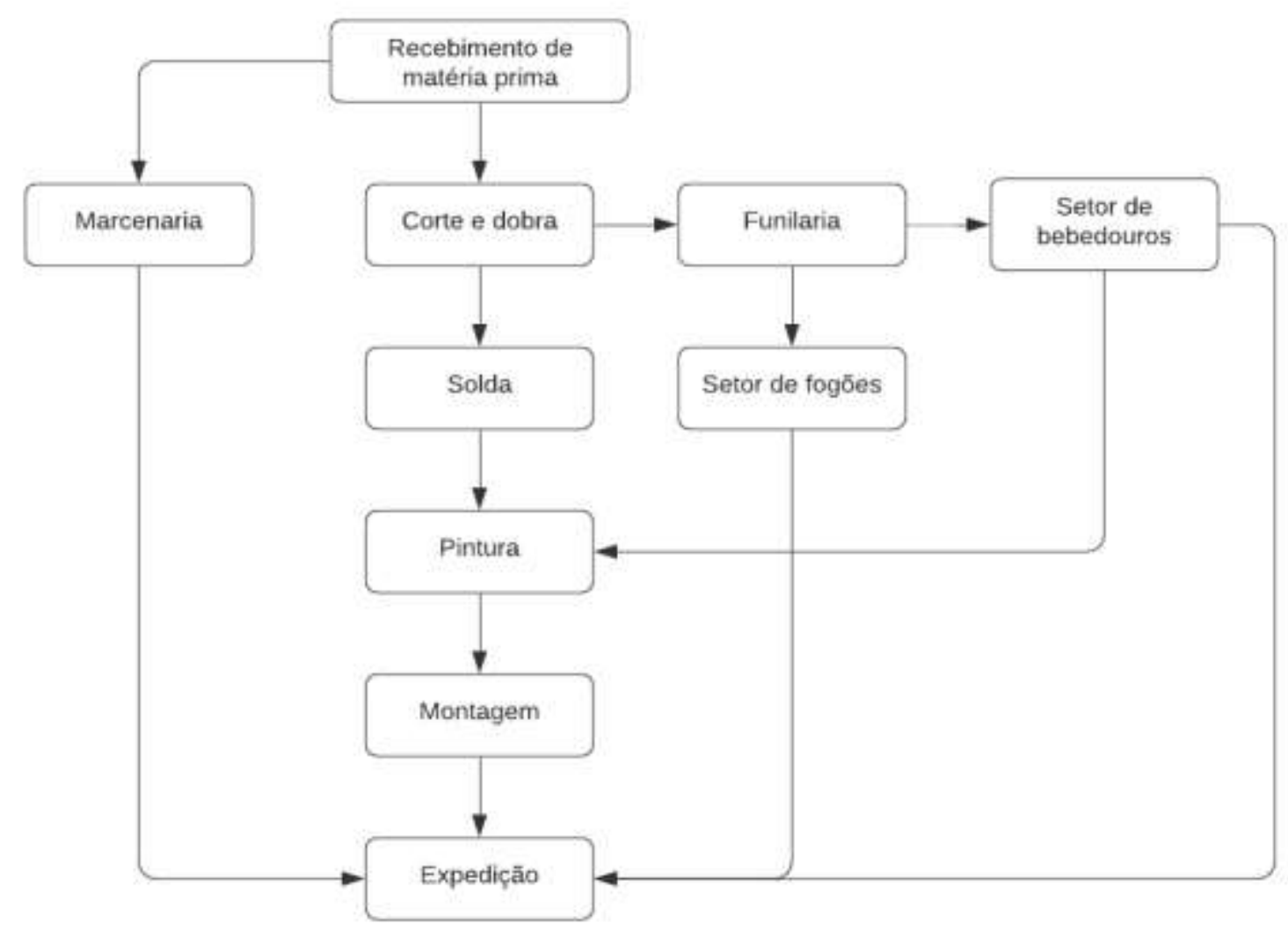

Fonte: Autores (2021).

A principal matéria prima utilizada é o aço, recebido em formato de bobinas slitadas, que é a composição primária de 95\% dos produtos comercializados pela empresa, os outros 5\% são representados pelos materiais MDP, melamínico e compensado. No corte e dobra, os recursos utilizados são 5 máquinas perfiladeiras, 8 guilhotinas, 6 máquinas policortes, a solda é composta por 5 cabines com máquinas de solda e na pintura, 1 máquina de pintura eletrostática e 3 cabines individuais para pintura a jato.

Por ter uma estrutura complexa e um mix elevado de produtos, um dos principais impasses deve-se ao fato do maquinário e mão de obra pararem constantemente suas atividades sem que haja uma programação elaborada, o que ocasiona em ociosidade e posteriormente, na sobrecarga dos equipamentos e colaboradores em razão da necessidade de produzir em larga escala e em um curto espaço de tempo, buscando atender os prazos dos pedidos.

\subsection{Análise e estratificação dos registros de paradas}

Nas perfiladeiras, que são automáticas, existem dispositivos denominados Adam, cuja função é captar os sinais dos sensores que estão acoplados no maquinário e enviar a informação para o sistema onde é feito o "apontamento de produção", 
interligado ao ERP da empresa. Quando o equipamento está ligado, ou seja, quando o sensor sente a pulsação dos recipientes de armazenamento, situados no final das perfiladeiras, que ficam mais pesados conforme a quantidade de peças produzidas forem sendo despejadas nos depósitos, os aparelhos situados no pé da máquina informam que o recurso está no status "Em produção", assim que o Adam não recebe os sinais de movimento, o sistema entra automaticamente no status "PNI - Parada Não Identificada" e são os operadores que alteram essas pausas informando em tempo real o que aconteceu.

No próprio sistema onde é realizado o apontamento são gerados relatórios de produtividade de cada equipamento para acompanhamento dos gestores da área, servindo também como base para formação dos indicadores de desempenho. No aparelho localizado no pé de máquina que fica logado no ERP para monitoramento real dos níveis de produção, das paradas e das ordens, também se encontra um cronômetro que contabiliza os tempos de cada registro gravando tais dados no sistema e reiniciando a contagem a cada mudança na classe de cada recurso.

Desta forma, foi possível extrair a base de dados de produtividade filtrando pelo setor de corte e dobra, em especial, área das perfiladeiras em um período de 3 meses, onde foi feito um compilado dos tempos decorridos por paradas produtivas e por falta de insumos, como apresentado no Figura 1. Foi levado em consideração apenas um turno de trabalho e as paradas produtivas relevantes para a construção do gráfico são as que se enquadram em paradas não inerentes ao processo, portanto não planejadas, para que assim possa ser feito um comparativo justo com as paradas por ausência de insumo, também inerentes ao processo.

Figura 3 - Estratificação de tempos decorridos nas paradas das perfiladeiras.

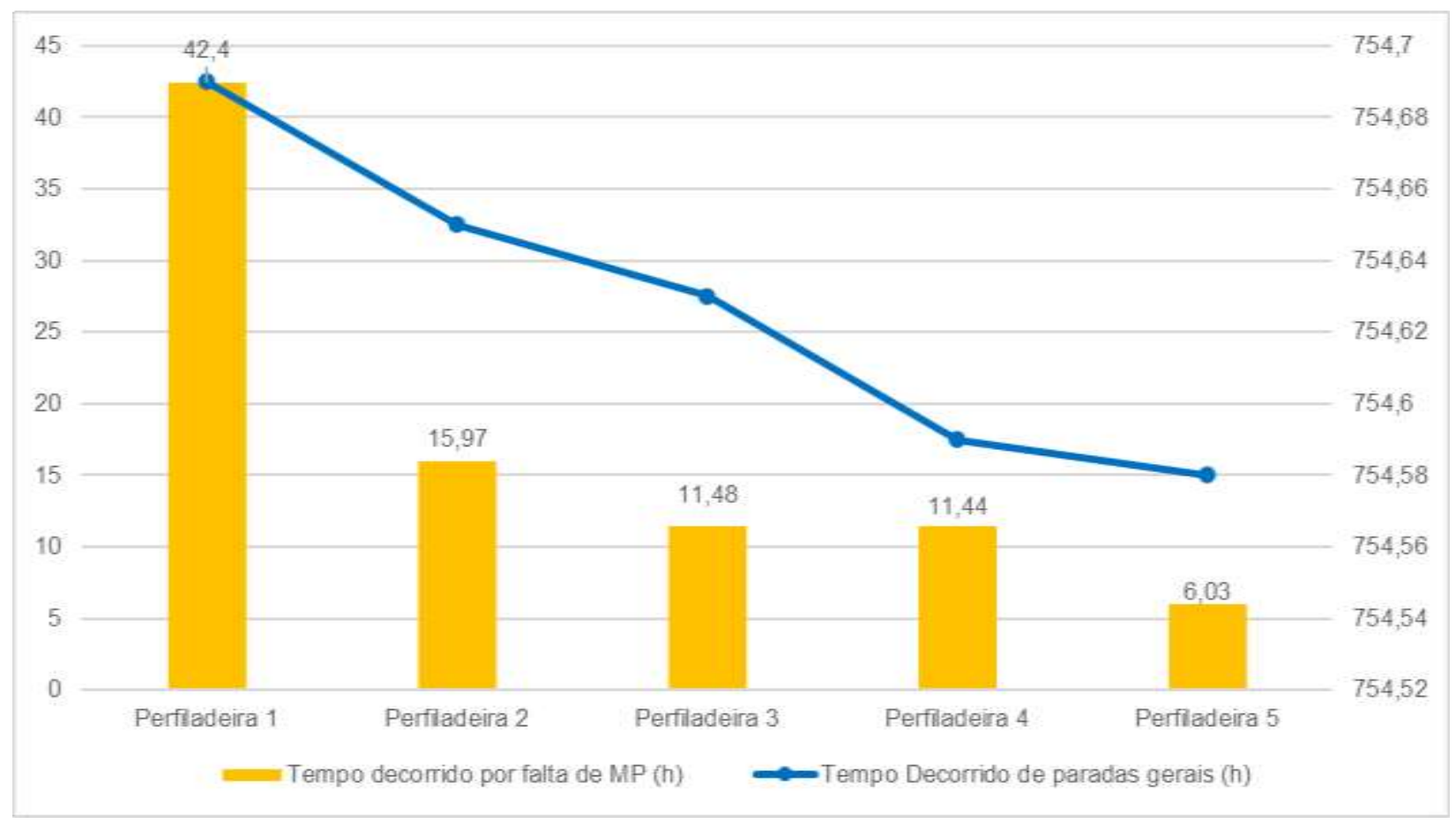

Fonte: Autores (2021).

$\mathrm{Na}$ representação acima, foram excluídos os tempos de paradas para refeição (1 hora), fora de turno (que consistem nos períodos em que a fábrica não funciona -16:48 às 22:30h) e o status registrado como "outros" que são aqueles que não se encaixam em nenhum código de paradas registradas. Desse modo, nota-se que a perfiladeira 2 apontou o maior índice de paradas não programadas, passando 326,33 horas com a produção interrompida e a perfiladeira 1 apresentou a pausa de 42,4 horas de maquinário parado por falta de matéria prima. 
O cálculo de capacidade/hora do equipamento foi feito aplicando a média da união dos registros com a quantidade de toneladas produzidas diariamente em cada máquina e dividindo pela quantidade de horas em que o processo ocorreu, sem interrupções. Os fatos foram resgatados do software que elabora relatórios de produção diária/semanal/mensal e, como dito anteriormente, os tempos decorridos. Considerando informações de paradas por falta de insumos ocorridas apenas no turno 1 (7:00 às 16:48, com exceção do tempo de refeição), extraindo os dados de produtividade mensais e anotando o tempo decorrido através do filtro de status "Em produção" encontra-se resultados de capacidade/h conforme citado na Quadro 3.

Quadro 3 - Capacidade produtiva x Quantidade de dias de maquinário parado.

\begin{tabular}{|c|c|c|}
\hline RECURSO & $\begin{array}{c}\text { CAPA CIDADE PRODUTIVA } \\
\text { TURNO 1 (EM TONELADAS) }\end{array}$ & $\begin{array}{c}\text { QUANTIDADE DE DIAS } \\
\text { DE PARADA (NO } \\
\text { TRIMIESTRE) }\end{array}$ \\
\hline Perfiladeira 1 & 1,32 & 5 \\
\hline Perfiladeira 2 & 12,6 & 2 \\
\hline Perfiladeira 3 & 0,41 & 1 \\
\hline Perfiladeira 4 & 0,24 & 1 \\
\hline Perfiladeira 5 & 0,27 & 10 \\
\hline Total Geral & 14,84 & \\
\hline
\end{tabular}

Fonte: Autores (2021).

À vista dos dados expostos na tabela acima, percebe-se que o total de parada representa aproximadamente $15 \%$ dos dias de funcionamento da empresa no trimestre. Considerando os dados da capacidade e multiplicando pela quantidade de dias de pausa em cada máquina, os resultados obtidos foram uma perda de produção de 6,6 toneladas de material na perfiladeira 1; $25,2 \mathrm{t}$ na perfiladeira $2 ; 410 \mathrm{~kg}, 240 \mathrm{~kg}$ e $270 \mathrm{~kg}$ nas perfiladeiras 3,4 e 5, respectivamente. Em suma, foram $148.400 \mathrm{~kg}$ de material desperdiçado por falta de um planejamento eficaz de compra, estoque e programação da produção que reduza significativamente estes números.

\subsection{Impacto das paradas nos produtos acabados}

No sistema ERP da empresa apresenta uma aba que permite que os almoxarifes informem a data da parada de produção, qual item estava em falta e qual produto acabado seria impactado com essa ausência. Desta forma, foi possível elaborar um painel de controle que extraía um compilado dos dados do trimestre e transformava em gráfico para que a visualização ficasse mais clara, como apresentado na Figura 3.

Figura 4 - Impactos da falta de matéria prima nos produtos acabados.

\begin{tabular}{|r|c|}
\hline Refrigerador Industrial & $50,00 \%$ \\
\hline Balcão Térmico Gelado & $14,40 \%$ \\
\hline Fornos & $9,50 \%$ \\
\hline Fogão Industrial & $7,50 \%$ \\
\hline Balcão Frigoríico Tendal & $6,30 \%$ \\
\hline Roupeiro de Aço & $4,20 \%$ \\
\hline Barcão Térmico Estufa & $3,60 \%$ \\
\hline Aôndola Semírio Estante & \\
\hline
\end{tabular}

Fonte: Autores (2021). 
É notório que o produto acabado que mais sofreu impacto das paradas foi o refrigerador industrial. Este produto é composto por matérias primas "únicas", ou seja, que não podem ser substituídas por outras existentes no almoxarifado, como os demais produtos. Portanto, o consumo desse material deve ser estudado e suas compras feitas antecipadamente.

Foi elaborada a curva $\mathrm{ABC}$ para entender a importância desses materiais no portfólio da empresa e, a partir disso, elaborar uma estrutura de melhorias buscando formas de reduzir a ausência desses itens no almoxarifado e a perda de produção dos mesmos."

Figura 5 - Curva $\mathrm{ABC}$ dos produtos acabados.

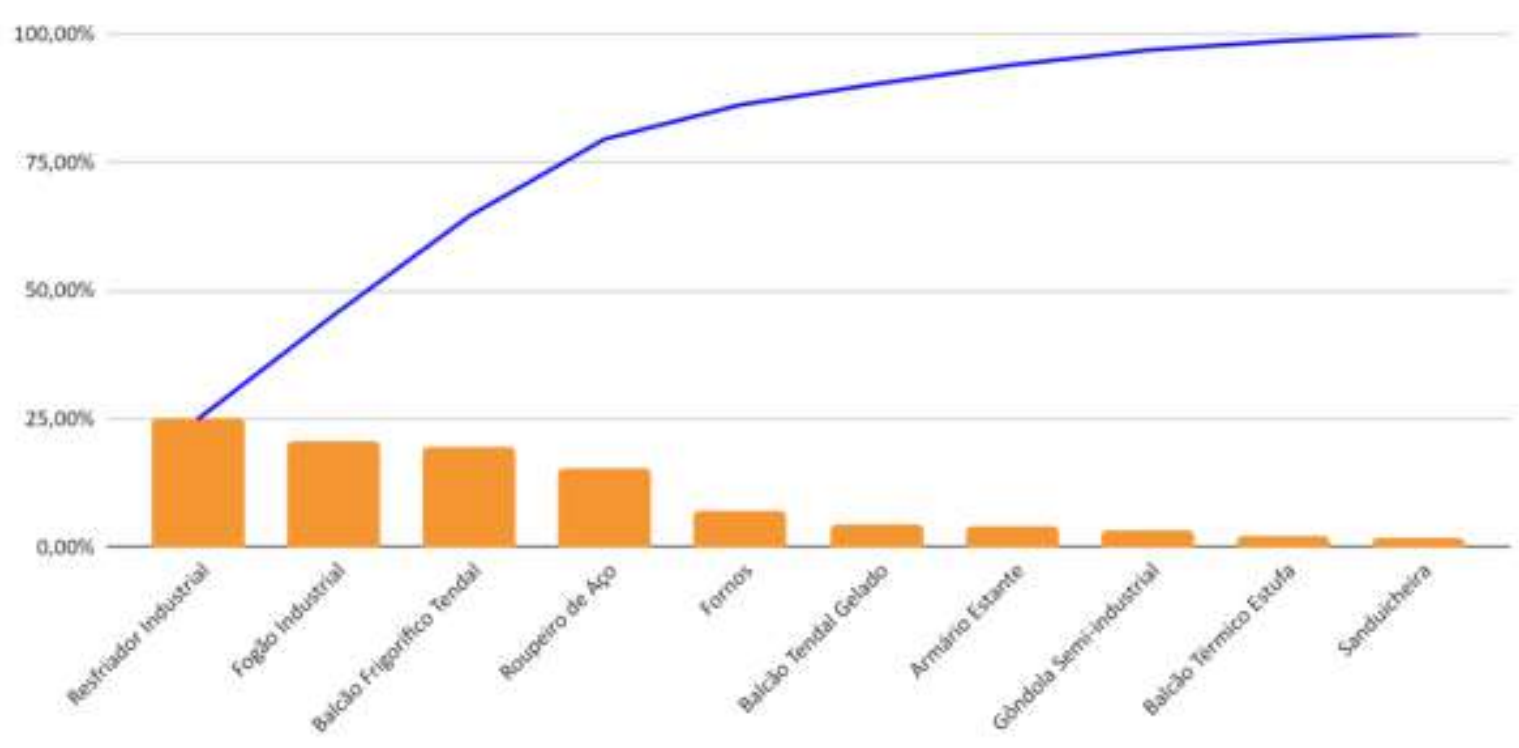

Fonte: Autores (2021).

Quadro 4 - Classificação dos Produtos Acabados.

\begin{tabular}{|c|c|c|}
\hline PRODUTOS & \% ACUMULADA & CONCEITO \\
\hline Resfriador Industrial & 24,90 & $\mathrm{~A}$ \\
\hline Fogão Industrial & 45,17 & $\mathrm{~A}$ \\
\hline Balcão Frigorífico Tendal & 64,47 & $\mathrm{~A}$ \\
\hline Roupeiro de Aço & 79,52 & $\mathrm{~A}$ \\
\hline Fornos & 86,18 & $\mathrm{~B}$ \\
\hline Balcão Tendal Gelado & 90,21 & $\mathrm{~B}$ \\
\hline Armário Estante & 93,95 & $\mathrm{~B}$ \\
\hline Gôndola Semi-industrial & 96,80 & $\mathrm{C}$ \\
\hline Balcão Térmico Estufa & 98,60 & $\mathrm{C}$ \\
\hline Sanduicheira & 100,0 & $\mathrm{C}$ \\
\hline
\end{tabular}

Fonte: Autores (2021).

Para elaboração da curva foram necessários os números de produção desses itens no período de 1 ano juntamente com os valores de venda de cada um, para que assim fosse possível visualizar quais PA (produtos acabados) tem mais giro no mercado. Partindo desse ponto, é notável que 4 dos 9 itens expostos na Figura 3, são classe A, ou seja, correspondem a 80\% 
dos materiais que mais geram rotatividade da empresa, dentre eles, o resfriador industrial que registra o maior impacto por falta de MP.

\subsection{Aplicação da Curva ABC e melhorias no processo}

Considerando os registros colocados no sistema pelos almoxarifes, como citado no tópico 3.3, foi construído uma planilha contendo a descrição do componente que estava em falta no momento da parada produtiva. Através dessa informação fica mais claro quais itens merecem um cuidado maior no momento da compra. No quadro 6 estão descritos quais produtos faltaram no estoque com maior frequência e suas respectivas quantidades. As matérias primas de maior frequência de falta na produção devem estar no radar do setor de compras e estoque para que não haja ausência das mesmas, pois, como demonstrado na Figura 4, todos esses itens estão caracterizados como elementos classe A. Portanto, é visível que esses insumos causam um impacto grandioso no momento da falta, principalmente pelo fato de não haver substituto para eles no almoxarifado. Com a falta dos mesmos, o maquinário e mão de obra param seus processos.

Quadro 5 - Relação de matérias primas mais faltantes no estoque.

\begin{tabular}{|c|c|c|}
\hline MATÉRIA PRIMA & $\begin{array}{c}\text { QUANTIDADE } \\
\text { (unidade) }\end{array}$ & $\begin{array}{c}\text { FREQUENCIA (no } \\
\text { trimestre) }\end{array}$ \\
\hline Injetor & 25 & 15 \\
\hline Compressor & 16 & 13 \\
\hline Filtro de Ar Primário & 11 & 10 \\
\hline Tinta em Pó Cinza & 5 & 3 \\
\hline Condensador 2777 & 2 & 1 \\
\hline Pé Nivelador & 1 & \\
\hline
\end{tabular}

Fonte: Autores (2021).

Para propor soluções para este problema foi necessário a elaboração de uma curva ABC dos itens do almoxarifado para entender o giro das MP, relacionadas na tabela acima, dentro do estoque. Deste modo, para construção da curva, foi preciso consultar o relatório de entradas e saídas de MP dentro do almoxarifado, considerando um período de 1 ano, para compreensão da quantidade de consumo dos materiais, além dos seus respectivos valores de mercado. 
Figura 6 - Curva ABC das Matérias Primas.

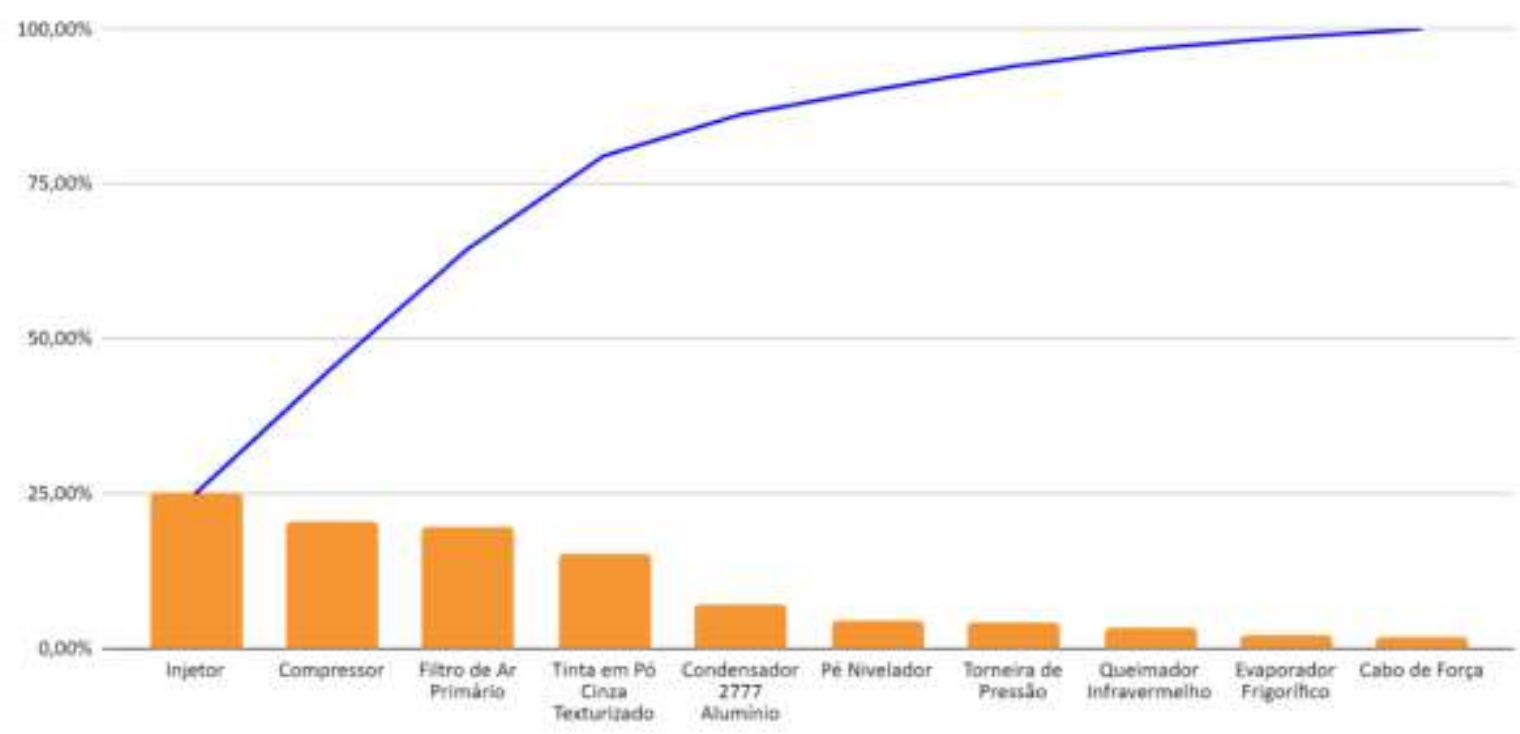

Fonte: Autores (2021).

Com o auxílio da Figura 4 verifica-se que os itens que apresentaram maior ausência no momento da produção, pertencem a classe A, sendo assim, compõem $80 \%$ do valor total movimentado e proporcionam maior rotatividade dentro do almoxarifado.

Em consonância com todos os dados mostrados nesta seção, é perceptível a necessidade de uma gestão ativa, organizada e de alinhamento entre os setores de produção e compras. No Quadro 7 foram evidenciadas as principais sugestões que devem ser feitas a fim de melhorar os processos citados.

Quadro 6 - Relação de sugestões de melhorias.

\begin{tabular}{|c|}
\hline Proposições de melhorias dos processos \\
\hline Mapeamento e conclusão das listas de materiais dos produtos acabados \\
\hline Execução da funcionalidade MRP \\
\hline Rotina de Inventários Rotativos de acordo com a curva ABC \\
\hline Elaboração de indicadores de acuracidade \\
\hline
\end{tabular}

Fonte: Autores (2021).

Faz-se necessário um mapeamento das listas de materiais dos produtos acabados classificados como A (Figura 3), pois com a conclusão delas é viável a execução do MRP, que já é uma ferramenta do próprio sistema da empresa. Caso haja no sistema um produto acabado contendo os componentes e suas respectivas quantidades corretas, o setor de compras receberia a demanda de implantação do pedido e o próprio sistema realizaria o cálculo da quantidade com os itens que seriam solicitados, já considerando o lead time dos fornecedores e estoques de segurança.

É imprescindível que seja realizado uma rotina de inventários rotativos no almoxarifado, para evitar furos e garantir que os estoques estejam sempre atualizados corretamente, além do desenvolvimento de indicadores de acuracidade que permitem o controle assíduo da confiabilidade entre os saldos reais e no sistema. 


\section{Conclusão}

As ferramentas de gestão de controle de materiais, tais como: curva ABC, inventários rotativos, MRP e indicadores de acuracidade são de suma importância para garantir que os estoques estejam bem administrados e que os resultados sejam garantidos. Neste artigo foram utilizadas tais técnicas como tratativas do problema de parada produtiva por falta de MP que afetava consideravelmente nos resultados de produtividade dos itens de maior demanda e rotatividade da empresa.

A pesquisa obteve êxito, pois os objetivos foram atingidos através da demonstração de análises das paradas produtivas gerais, descrição da ocorrência das mesmas por falta de insumos, visualização dos componentes que mais faltaram no estoque, os produtos acabados mais afetados, construção da curva abc de produtos acabados e componentes para evidenciar o impacto da ausência desses itens no processo e propor melhorias para reduzir ou eliminar esse gargalo.

Esta pesquisa agrega bastante conhecimento na área de gestão de operações e processos. Desta forma, este estudo pode trazer ricas contribuições nos futuros trabalhos que envolvam a área de processos, planejamento, programação de necessidade e servir como base para consolidar a resoluções dos impasses a partir da utilização da curva ABC. Além de agregar e aprimorar habilidades de identificação de problemas, destacar a aplicação das ferramentas utilizadas e garantir que haja um crescimento da visão sistêmica dos processos.

É preciso organizar e concluir as listas de materiais, concluir o calendário de inventários rotativos e colocar em prática o MRP que ainda não é utilizado na empresa, para estreitar o contato entre as equipes de PCP e compras.

\section{Referências}

Bento, A. R., Tambosi, S. L, \& Prus, E. M. (2013, agosto). Utilização da tecnologia MRP como melhoria no planejamento da produção em uma indústria automotiva. Contribuição técnica ao $68^{\circ}$ Congresso Anual da ABM - Internacional. Belo Horizonte, MG, Brasil. 2013.

Bertaglia, P. L. (2006). Logística de gerenciamento da cadeia de abastecimento. (4a ed.) Saraiva.

Betts, A., Chambers, S., Jonhston, Robert, \& Slack, Nigel. (2013). Gerenciamento de Operações e de Processos: princípios e práticas de impacto estratégico. (2a ed). Bookman.

Borges C. T., Campos S. M., \& Borges C. E. (2010) Implantação de um sistema para o controle de estoques em uma gráfica/editora de uma universidade. Revista Eletrônica Produção \& Engenharia, 3(1), 236-247.

Brown, K. L, Inman R. A., \& Calloway J. A. (2001). Measuring the efects of inventory inaccuracy in MRP inventory and delivery performance. Production Planning \& Control, 12(1), 46-57.

Corrêa, H. L., Gianesi, I.G. N., \& Caon, M. (2010). Planejamento, Programação e Controle da Produção. (5a ed.) Atlas.

Costa, Fábio J. C. Leal. (2002). Introdução à administração de materiais em sistemas informatizados. IE Editora.

Dias, M. A. P. (2010). Administração de materiais: uma abordagem logística. (4a ed.). Atlas.

Fernandes, F. C. F., \& Godinho, M. Filho. (2010). Planejamento e Controle da Produção: dos fundamentos ao essencial. Atlas.

Fernandes, L. A., \& Pires, S. R. I. (2005). Impactos da falta de acurácia de estoques e proposições para melhorias: estudo de caso em uma empresa fabricante de autopeças. XII SIMPEP: Simpósio de Engenharia de Produção. Bauru, SP, Brasil.

Gil, A.C. (1994). Métodos e técnicas de pesquisa social. (4a ed.). Atlas.

Gonçalves, P. S. (2013). Administração de materiais. (7a ed.), Elsevier.

Leal, G. C. L., Cotrim, S. L., \& Nardotto, J. (2016). Utilização do Método de Custeio ABC como Instrumento de Gestão em uma Lanchonete de Pequeno Porte. Revista da Micro e Pequena Empresa. Campo Limpo Paulista, 10(1), 80-91. http://www.spell.org.br/documentos/ver/41272/utilizacao-do-metodo-decusteio-abc-como-instrumento-de-gestao-em-uma-lanchonete-de-pequeno-porte.

Letti, G. C, \& Gomes L. C. (2014). Curva ABC: Melhorando o gerenciamento de estoques de produtos acabados para pequenas empresas distribuidoras de alimentos. 1(2), 66-86.

Lopes, C. B., Silva, R. H. da, \& Rocha, W. A. (2014). Sistemas de produção MRP \& MRP II. REGRAD - Revista Eletrônica de Graduação do UNIVEM. 6(1), 1984-7866. https://revista.univem.edu.br/REGRAD/article/view/440.

Oliveira, L. M., Chieregato, R., Gomes, M. B., \& Peres, J.H. Jr. (2009). Manual de contabilidade tributária: textos e testes com as respostas. (8a ed.). Atlas.

Pozo, H. (2002). Administração de recursos materiais e patrimoniais: uma abordagem logística. (2a ed.). Atlas. 
Research, Society and Development, v. 10, n. 7, e4010716259, 2021

(CC BY 4.0) | ISSN 2525-3409 | DOI: http://dx.doi.org/10.33448/rsd-v10i7.16259

Razzolini, E. Filho. (2012). Administração de Material e Patrimônio. IESDE Brasil.

Rekik, Y. (2006). The Impact of the RFID Technology in Improving Performance of Inventory Systems subject to Inaccuracies. Tese de Doutorado em Engenharia Industrial. École Centrale des Arts et Manafactures, Paris.

Ribeiro, M. Y. D., Carmo, E. P., Lobato, B. C., Pinho, A. P. S., \& Lopes, H. S. (2015, outubro). Aplicação do mrp como ferramenta para o planejamento e controle da produção em uma indústria de cabos elétricos de alumínio. XXXV Encontro Nacional de engenharia de produção: Perspectivas Globais para a Engenharia de Produção, Fortaleza, CE, Brasil. http://www.abepro.org.br/biblioteca/TN_STP_206_221_27199.pdf.

Rodrigues, M. D., \& Inácio, R. O. (2010, novembro). Planejamento e Controle da Produção: Um estudo de caso em uma empresa metalúrgica. INGEPRO: Inovação, Gestão e Produção. São Paulo, SP, Brasil. http://www.ingepro.com.br/Publ_2010/Nov/325-921-1-PB.pdf .

Santos, J. G., Victor, D.L., \& Silva, S. S. F. (2010, outubro). Planejamento e Controle de Produção: um estudo de caso em uma indústria de calçados de Campina Grande - PB. XXX Encontro Nacional de engenharia de produção: Maturidade e desafios da Engenharia de Produção: competitividade das empresas, condições de trabalho, meio ambiente, São Carlos, SP, Brasil. http://www.abepro.org.br/biblioteca/enegep2010_tn_sto_113_739_17576.pdf.

Severo, J. F. (2006). Administração de logística integrada: materiais, PCP e marketing, E-papers.

Silva, J. R. D, \& Henzel, M.E. (2012). Gestão de Estoques: Fator decisivo para a lucratividade organizacional. Iberoamerican Journal of Industrial Egineering, 4(7), 100-117. Brasil.

Suzano, M. A. (2013). Administração da produção e operações com ênfase em logística. Interciência.

Vago, F. R. M., et al (2013). A importância do gerenciamento de estoque por meio da ferramenta curva ABC. Revista Sociais e Humanas - Universidade Federal do Rio Grande do Sul, Porto Alegre, RS, Brasil. 26(3), 638-655. https://periodicos.ufsm.br/sociaisehumanas/article/view/6054/pdf.

Waller, M. A., Nacthmann, H., \& Hunter, J. (2006). Measuring the impact of inaccurate inventory information on a retail outlet. The International Journal of Logistics Management, 17(3), 355-376. 